\title{
Art Students Who Cannot Draw: Exploring the Relations Between Drawing Ability, Visual Memory, Accuracy of Copying, and Dyslexia
}

\author{
I. C. McManus, Rebecca Chamberlain, \\ and Phik-Wern Loo \\ University College London
}

\author{
Howard Riley \\ Swansea Metropolitan University
}

\author{
Qona Rankin \\ Royal College of Art
}

Nicola Brunswick

Middlesex University

\begin{abstract}
Some art students, despite being at art school, cannot draw very well, and would like to be able to draw well. It has been suggested that poor drawing may be a particular problem for students with dyslexia (and a high proportion of art school students is dyslexic). In Study 1 we studied 277 art students, using a questionnaire to assess self-perceived drawing ability and a range of background measures, including demography, education, a history of dyslexia, a self-administered spelling test, and personality and educational variables. In Study 2 we gave detailed drawing tests to a sample of 38 of the art students, stratified by self-rated drawing ability and spelling ability, and to 30 control participants. Students perceiving themselves as good at drawing did indeed draw better than self-perceived poor drawers, although the latter were still better than non-art student controls. In neither Study 1 nor Study 2 did skill at drawing relate to dyslexia or spelling ability, and neither did drawing ability relate to any of our wide range of background measures. However Study 2 did show that drawing ability was related both to ability at copying simple angles and proportions (using the "house" task of Cain, 1943), and also to visual memory (as suggested by Jones, 1922), poor drawers being less good at both immediate and delayed recall of the Rey-Osterrieth complex figure.
\end{abstract}

Keywords: art students, drawing ability, visual memory, Rey-Osterrieth complex figure, dyslexia

Drawing, the making of an accurate representation of the visual world to express form upon a plane surface (Speed, 1913), was central to the visual arts in the West from the early Renaissance until the beginning of the 20th century. That changed dramatically in the 20th century with the advent of Modernism. The change in attitude was typified by Picasso's comment at an exhibition of

I. C. McManus, Rebecca Chamberlain, and Phik-Wern Loo, Research Department of Clinical, Educational and Health Psychology, Division of Psychology and Language Sciences, University College London; Qona Rankin, Royal College of Art; Howard Riley, Dynevor Centre for Art, Design and Media, Swansea Metropolitan University; and Nicola Brunswick, Department of Psychology, School of Health and Social Sciences, Middlesex University.

We are grateful to Arnold Wilkins and Neil Martin for their helpful discussions and comments, to Niki Daniel for scoring the Rey-Osterrieth figures, to Arnold Wilkins for his careful reading of the manuscript, and to Christopher Kennard, Chris Frith, Uta Frith, Tony Morland, Michael Morgan, Dominic Ffytche, Johannes Zanker, Alan Cummings, Denisse de Cordova, and Amelia Johnston, and other participants in the Drawing and Dyslexia Study Group at the RCA for their discussion of the issues surrounding this research study.

Correspondence concerning this article should be addressed to I. C. McManus, Research Department of Clinical, Educational and Health Psychology, Division of Psychology and Language Sciences, University College London, Gower Street, London WC1E 6BT, UK. E-mail: i.mcmanus@ ucl.ac.uk children's drawings that, "When I was the age of these children I could draw like Raphael; it took me many years to draw like these children" (Read, 1956). McMahon (2002) has described the modes of drawing of the expert (the artist) and the nonexpert (the child) as structural and denotative, denotative drawing being charmingly shown in the child who said, "First I think and then I draw my think" (Gill, 1940). Structural drawings-visually accurate representations-were defined operationally by Cohen and Bennett (1997) as those "that can be recognized as a particular object at a particular time and in a particular space, rendered with little addition of visual detail that cannot be seen in the object represented or with little deletion of visual detail" (p. 609).

The role of drawing changed enormously in the 20th century (Duff \& Davies, 2005), drawing being neither necessary nor sufficient for attainment or acclaim in art school or the art-world. Drawing — the "rationalization of sight" (Ivins, Jr., 1938)—remains though a skill central to much artistic practice. John Berger used a justification similar to that of John Ruskin (1857): "drawing... forces the artist to look at the object in front of him, to dissect it in his mind's eye and put it together again" (Berger, 2005). Drawing is also increasingly seen as visual problem solving (Duff \& Davies, 2005), and hence as central to many nonartistic practices, as in design, advertising, medicine, engineering, and science (Miller, 2006). Drawing may also improve spatial visualization skills (Alias, Gray, \& Black, 2002). Drawing is so central to technical and practical life that Maynard (2005) has suggested that, 
"drawing would be an absolute necessity for modern life even if there were no art to it" (p. 230).

Although drawing is no longer essential for artistic practice, in recent years there has been a growing concern among teachers at art and design schools that some art and design students do not draw at all well. More crucially, those same students would like to draw better and to use drawing within their practice. At the Royal College of Art (RCA) in London, which is entirely a postgraduate institution, students on all courses, both fine arts, such as painting and sculpture, and more applied courses, such as textiles, jewelry-making, and ceramics, have reported problems with drawing. In particular practical problems arose for students who practiced very competently in their particular medium, but could not draw. A typical problem is shown by a fashion student who puts on a show in London, and is later phoned from New York: "We like your work very much. Could you please fax through drawings of some other of your ideas?" At that point a student realizes that drawing was a practical skill they both lacked and needed. In the spring of 2005, one of us (Q.R.) interviewed a series of postgraduate students at the RCA reporting problems with drawing. The following two extracts were instrumental in setting up the present study, and give a good idea of the problems:

"I always used to photograph stuff, and then photocopy the photographs, and then what you get is a very linear, black and white, flat-um-sort of image of what you were trying to portray. So that's taken that image down from 3D garments to 2D flat which can be then redrawn over into an illustration. So it's a really lengthy process. [...] I had a massive problem on my BA-I actually got told by tutors that I couldn't draw and stuff." [Female student on the Textiles course]

"I'm quite good if I concentrate at drawing, I can look at something and draw it but it's never you know an amazing drawing. It's more when I have to do something on the spot, sketchy, that things start to go wrong and I'll draw a shape - I'll try and draw a circle and it's never a circle, I can never do what I want what I can see in my head I can't really get it on the paper - um - so one of the things that happens is that if I've got a client then I [pause] I'm drawing them a cross-section of a ring so they get the idea of what the shape might be like it's, it's — I just confuse people [laughs] so that can be quite embarrassing, especially if they're - you know - they're going to give me money for something and they just think I can't even draw very well." [Female student on the Jewellery course]

As it happened, both of those students, as well as others with drawing problems, were dyslexic, and the possibility was raised that dyslexia was associated with problems with drawing. The present study was therefore set up to assess the extent to which dyslexia and also other background factors may or may not be important in explaining why some art students cannot draw. Here we briefly review some of the factors that have been invoked in explaining differences in drawing ability, and which we wished to include in our study.

\section{i. Dyslexia}

A high proportion of students in art schools (and probably also students in drama colleges and other arts-related courses) have difficulty in reading and writing, are formally diagnosed as dyslexic (Rankin, Riley, \& Davies, 2007; Woolf \& Lundberg, 2002), and have problems with verbal processing and spelling (Winner, Casey, DaSilva, \& Hayes, 1991; Winner \& Casey, 1992; Hassler, 1990). Nevertheless, dyslexia is certainly compatible with producing work of outstanding artistic ability (Aaron \& Guillemard, 1993). There are also suggestions that the drawing style of dyslexic art students may be different (Grant, 2008; Rankin et al., 2007; Rankin, Riley, \& Davies, 2005). Various explanations have been put forward to explain the high rate of dyslexia on visual arts courses. Dyslexia might make it difficult to study sciences or the humanities and hence, faut de mieux, dyslexics gravitate toward courses requiring nonverbal skills (Winner \& Casey, 1992; Winner, von Karolyi, \& Malinsky, 2000). Alternatively, dyslexic students may also have special talents, generally in the visual arts (Riley, 2008), or in visual spatial ability (Craggs, Sanchez, Kibby, Gilger, and Hynd, 2008; Miles, 1993; West, 1997), or particular spatial tasks (von Karolyi, 2001; von Karolyi \& Winner, 2004; Brunswick, 2007). However there are dissenting views on this "popular (and comforting) view" of compensatory talents in dyslexia (Winner et al., 2000; Winner et al., 2001). Finally, since drawing is in part a symbolic act of representing the visual world by arbitrary marks, then dyslexic readers may also have specific problems with making marks in drawing.

\section{ii. Handedness and Lateralization}

One can hardly consider drawing without referring to Betty Edwards' popular, best-selling book, Drawing on the right side of the brain (Edwards, 1989). Although Edwards' metaphoric use of the right hemisphere is effective, the exercises described are often typical of those anyway carried out in art schools, and it is possible that any benefit comes primarily from improving motivation and attention, and hence are no more effective than nonspecific training (Chambliss \& Moulton, 1987). Direct evidence for hemispheric involvement in drawing is limited, functional magnetic resonance imaging studies suggesting that drawing in nonartists is characterized by bilateral parietal lobe activation (Makuuchi, Kaminaga, \& Sugishita, 2003). In one study drawings made with the left hand were judged as aesthetically superior to those drawn by the right hand (Magnus \& Laeng, 2006). Left-handedness has been said to be more frequent in visual artists (Mebert \& Michel, 1980), although that has been disputed (Lanthony, 1995; Lanthony, 2005). The denotative drawings of most children contrast dramatically with the exceptional structural drawing found in some children and adults with autism (Arnheim, 1980; Mottron \& Belleville, 1993; Golomb \& Schmeling, 1996; Milbrath \& Siegel, 1996), with perspective being rendered particularly accurately (Mottron \& Belleville, 1995). Although most autistic individuals do not show drawing talents (Fein, Lucci, \& Waterhouse, 1990; McGregor, 1990; Hermelin, Pring, \& Heavey, 1994), there is nevertheless a contrast with the poor drawing found in Williams' syndrome (Bertrand, Mervis, \& Eisenberg, 1997). Based on the exceptional abilities found in autism, Snyder has argued that drawing skills are normally present in the right hemisphere, but are usually suppressed by the overly dominant left hemisphere, a process suggested not to occur in autism (Snyder \& Thomas, 1997). Drawing in normal adults is also said to be 
enhanced by continuous transcranial magnetic stimulation to suppress the left fronto-temporal region (Snyder et al., 2003).

\section{iii. Problems in Copying}

Central to academic drawing is a need accurately to copy angles of lines and relative proportions of objects. One of the first to emphasize this was the artist, psychologist and art teacher Theron Cain (1946), working at the Massachusetts School of Art, who developed a simple measure we refer to as the "House task." Art students were asked to copy five six-sided polygons, consisting of a horizontal base, two vertical sides of different lengths, and three "roof" sections at various angles to one another, and described by Cain as resembling "oldfashioned houses." Cain (1943) found strong correlations between accuracy of portraying the houses, and subsequent grades obtained by the art students.

\section{iv. Visual Memory}

Most drawing in an artistic context (except when using a camera lucida or drawing on glass) involves looking at an object and then looking away to the drawing. That inevitably requires a short-term storage of the visual form so that after a few moments marks can be added to the drawing. Some art teachers encourage such memorization by purposely placing students between the model and the drawing board, so that the student must turn around and draw from memory, with no possibility of direct comparing object and representation. Jones (1922) found the drawing ability of 7th and 8th grade children correlated with a measure of visual memory, and a similar result was reported by Rosenblatt and Winner (1988). Superior visual memory has also been invoked to explain the exceptional drawing abilities found in autism (Waterhouse, 1988; Snyder \& Thomas, 1997; O'Connor and Hermelin, 1987), although generally children with autism do not have enhanced visual memory (Minshew \& Goldstein, 2001). The Rey-Osterrieth complex figure (Rey \& Osterrieth, 1993; Meyers \& Meyers, 1995) is a standard method for assessing visual working memory, first being copied, then recalled immediately, and then recalled after a delay. Of interest is that individuals with dyslexia also perform poorly, either generally (Mati-Zizzi and Zafiropoulou, 2003), or more specifically in those with poor mathematical skills (Helland \& Asbjørnsen, 2003).

\section{Rationale for the Present Study}

This paper describes two studies examining why some art students cannot draw, specifically looking for a relationship between drawing ability and dyslexia, and, following the insights of Jones (1922) and Cain (1943), relating drawing ability to visual memory, and the copying of angles and proportions. Study 1 was a wide-ranging questionnaire study assessing perceived problems in drawing in relation to formal educational qualifications, personality measures, dyslexia, spelling ability, and lateralization. Study 2 directly assessed drawing ability in selected students from Study 1, stratified by drawing ability and spelling ability, and also looked at a control group of non-art students.

\section{Study 1}

Study 1 used a questionnaire to assess the self-perceived drawing ability of a large group of art students.

\section{Method}

Participants. Participants consisted of 277 art students, who were postgraduates at the RCA, or foundation students at Swansea Metropolitan University (SMU; then Swansea Institute of Higher Education). The SMU participants consisted of an entire year group, whereas those at RCA were volunteers and therefore perhaps not entirely representative of art students in general.

Questionnaire. Participants at SMU and the RCA completed a questionnaire consisting of a single folded sheet of A3 paper (four sides of A4 paper, $297 \times 210 \mathrm{mms}$ ). The questionnaire included questions on:

1. Skills. Self-perceived abilities on 25 skills potentially important for success at art school, including skills specific to drawing and other visual media, and generic skills such as verbal creativity and using calculators. Each was assessed "in relation to other people studying art and design" (emphasis in original) on a five point scale from "much below average" (1) through "about average" (3) to "much above average" (5).

2. Aesthetic activities. Participation in 20 different aesthetic activities (e.g., listening to popular music, reading a novel, going dancing), including all of the topics assessed by McManus and Furnham (2006).

3. Lateralization. Six questions were asked on handedness, eyedness, and footedness, all of which had been included in previous studies (McManus \& Drury, 2004; McManus, Martin, Stubbings, Chung, and Mitchison, 2004). Since answers correlate, here we report only the hand used to hold a pencil for drawing a picture.

4. Right-left confusion. Five questions on right-left confusion (e.g., "Do you have difficulty when giving directions?") based on those of Hannay, Ciaccia, Kerr, and Barrett, (1990) and Jordan, Wüstenberg, Jaspers-Feyer, Fellbrich, and Peters (2006). The items were combined to produce a single right-left confusion score.

5. History of dyslexia. A single question asked if the student had ever been told they had developmental dyslexia ("Never," "No, but I've wondered if I might be dyslexic," and "Yes, I have been diagnosed as dyslexic"). Similar questions asked about dyspraxia and other motor problems, and about a history of stuttering/ stammering.

6. Self-administered spelling test. Everatt (1997) has shown that the best single predictor of dyslexia is spelling ability, so that for the present study we devised a self-administered spelling test, described in more detail elsewhere (Brunswick et al., in preparation), in which the correct spelling and three plausible alternatives were presented for 20 commonly misspelled words.

7. Personality. A 15 -item version of the Big Five personality questionnaire, using items from the NEO-FFI, that has been used extensively in previous studies (Furnham, McManus, \& Scott, 2003; Furnham \& McManus, 2004; McManus \& Furnham, 2006; McManus, Mitchison, Chung, Stubbings, and Martin, 2003). 
8. Educational qualifications. Students educated within the U.K. education system were asked about grades obtained at General Certificate of Secondary Education (GCSE; typically taken at age 15), and Advanced (A) level (typically taken at age 17) in the 27 commonest subjects, or in "other" subjects. Results were summarized as the average grade attained (scored as $A^{*}=6 ; A=5$; $\mathrm{B}=4 ; \mathrm{C}=3 ; \mathrm{D}=2 ; \mathrm{E}=1$; all others $=0$ ), and in addition specific grades were looked at in GCSE Art, English Language, and Math.

9. Demographics. Participants were asked their sex, age, nationality, and first language(s), and also whether their parents were either artists, or were "sympathetic" to the arts.

At the end of the questionnaire participants read a statement signed by one of us (I.C.M.) stating that the data were confidential, would be stored securely, and would only be used for the purposes of research. Students were also told that they could return the questionnaire anonymously, as it would still be of help, but we would prefer it if they could give us contact details and sign the questionnaire to indicate that we could contact them for a follow-up study.

Statistical analysis. Alpha was set at 0.05 . Where appropriate, a Bonferroni correction was applied.

Ethics. The study was approved by the Ethical Committee of the Department of Psychology of University College London.

\section{Results}

Participants. The questionnaire was completed by 277 art students (SMU: $N=90 ; 70 \%$ female; median age $=19$, quartiles $=19$ and 20); RCA: $N=187,55 \%$ female; median age $=27$, quartiles $=25$ to 29 ).

Self-rated drawing ability. Six of the self-report questions on abilities referred to drawing skills ("Drawing from observation (e.g., life-drawing)," "Drawing from imagination," "use of perspective, shading and shadow," "Confidence in mark making when drawing," "Use of contrast and tone in drawing," and "Technical drawing (geometric and engineering drawing"). Correlations between the six measures were all positive, although correlations between the technical drawing question and the others were relatively low (.060 to .288), and factor analysis suggested a separate factor. A scale was therefore created using just the first five drawing questions, which had a Cronbach's alpha of .813 (mean interitem correlation $=.469$, range $=.320$ to .652 ). The validity of the measure will be left until Study 2 is reported, where it will be shown that self-rated drawing ability correlated with the quality of drawings produced by participants. Figure 1 shows a histogram of mean self-reported drawing ability. While some students perceive themselves as very good at drawing (mean rating $=5$ ), and the majority perceive themselves as average to above average ( 3 to 4 ), there is a minority of students who perceive their drawing skills as below average (2) or much below average (1).

The spelling test and a diagnosis of dyslexia. A simple score of spelling ability, calculated as the total number of items correct out of 20, had a Cronbach's alpha of .801, and an overall mean of $73.9 \%$ (SD 16.5\%; quartiles $65 \%$ and $85 \%$, 5th percentile 40\%; 95\% percentile 95\%). Overall, 37/267 (13.9\%) students reported a definite diagnosis of dyslexia, and a further $55(20.6 \%)$ suspected that they may be dyslexic. The spelling

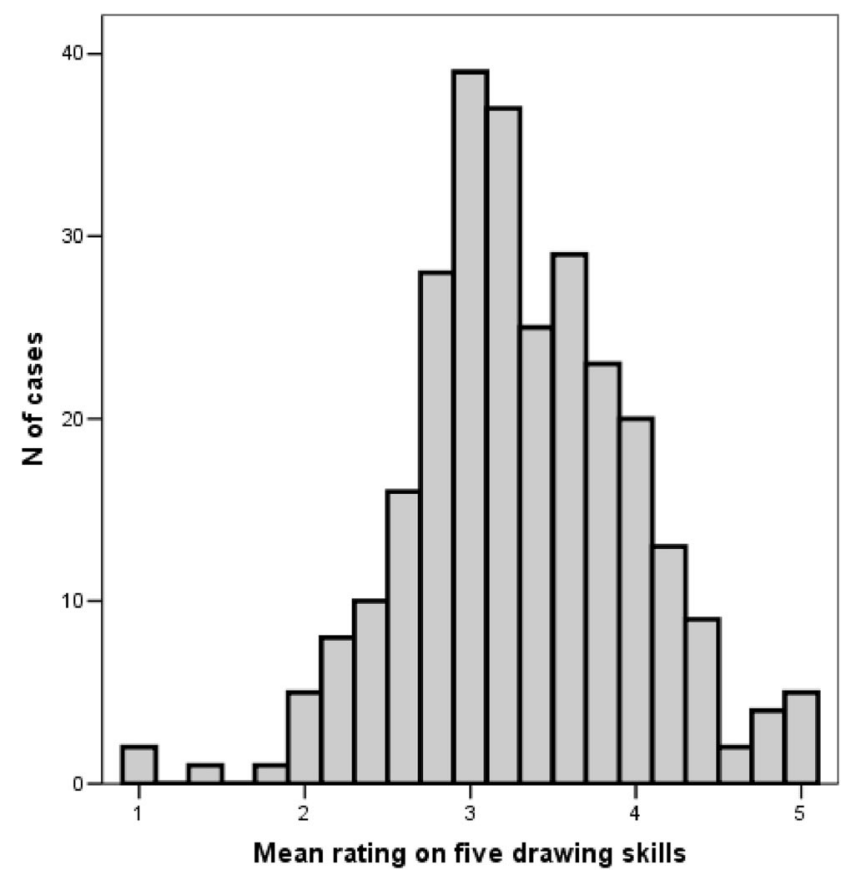

Figure 1. Distribution in Study 1 of self-rated drawing skills, based on five separate assessments of drawing (see text).

test scores for these three groups were significantly different, $F(2,262)=19.18, p<.001$. Post hoc tests showed that the group diagnosed as dyslexic had lower scores $(M=60.1, S D=$ 16.4 , range 30-90) than those who suspected that they might be dyslexic $(M=71.4, S D=16.6$, range 30-95), who were lower than those with no history of dyslexia $(M=77.4, S D=15.1$, range $25-100)$. The spelling test is therefore validated as an indicator of dyslexia, although clearly there are some individuals with low scores who appear not to be dyslexic and some individuals who are dyslexic who have high scores. The spelling test and self-reported history of dyslexia are therefore both reported in subsequent analyses.

Correlates of self-rated drawing ability. The self-rated drawing score was examined in relation to a number of background variables related to demography and family background in art, handedness and lateralization, dyslexia and other problems, individual difference variables, and educational achievement (see Table 1). Self-rated drawing score correlated at the 0.05 level with only one of the 22 variables shown in Table 1 $(p=.048)$, and that result clearly would not survive a Bonferroni correction. The lack of relationship of self-rated drawing score to the 22 background variables was confirmed using a multiple regression, which overall was not significant, $F(22$, $254=.834, p=.682$, and with only one of the 22 variables being nominally significant at $p<.05$, Sex, $t(254)=-2.126$, $p=.034$, although that result would not survive a Bonferroni correction. Purely on an exploratory basis, given their problems with overly liberal significance levels (Thompson, 1995), forward entry and backward removal regressions were also used. With forward entry regression, no variables were significant with $p<.05$. With backward removal, two variables remained 
Table 1

Correlations of Self-Rated Drawing Ability and Other Relevant Variables With Background Variables

\begin{tabular}{|c|c|c|c|}
\hline & Mean self-rated drawing ability & Diagnosis of dyslexia & Spelling test \\
\hline \multicolumn{4}{|l|}{ Demographics and background } \\
\hline $\operatorname{Sex}(1=$ male, $2=$ female $)$ & $-.116(p=.055)$ & $.062(p=.312)$ & $.025(p=.624)$ \\
\hline Age & $-.047(p=.443)$ & $.020(p=.747)$ & $.120(p=.052)$ \\
\hline Parents are artists & $-.031(p=.619)$ & $.146(p=.019)$ & $-.095(p=.123)$ \\
\hline Parents sympathetic to the arts & $.000(p=.996)$ & $.090(p=.152)$ & $-.025(p=.691)$ \\
\hline \multicolumn{4}{|l|}{ Lateralization and right-left problems } \\
\hline Hand to draw a picture & $-.005(p=.935)$ & $-.114(p=.065)$ & $-.006(p=.920)$ \\
\hline Right-left problems & $-.081(p=.180)$ & $.325(p<.001)$ & $-.165(p=.006)$ \\
\hline \multicolumn{4}{|l|}{ Spelling, dyslexia, dyspraxia, stuttering and stammering } \\
\hline Spelling test & $-.002(p=.975)$ & $-.352(p<.001)$ & 1 \\
\hline Diagnosis of dyslexia & $.022(p=.724)$ & 1 & $-.352(p<.001)$ \\
\hline Dyspraxia/motor problems & $-.050(p=.427)$ & $.418(p<.001)$ & $-.219(p<.001)$ \\
\hline Stuttering/stammering & $.011(p=.856)$ & $.194(p=.002)$ & $-.014(p=.826)$ \\
\hline Family history of dyslexia/stuttering/stammering & $.015(p=.816)$ & $.434(p<.001)$ & $-.103(p=.110)$ \\
\hline \multicolumn{4}{|l|}{ Individual difference measures } \\
\hline Aesthetic Activity score & $.094(p=.138)$ & $-.039(p=.547)$ & $-.063(p=.331)$ \\
\hline Big Five: Neuroticism & $-.037(p=.541)$ & $.308(p<.001)$ & $-.160(p=.009)$ \\
\hline Big Five: Extraversion & $-.010(p=.869)$ & $.053(p=.393)$ & $-.090(p=.144)$ \\
\hline Big Five: Openness to experience & $-.042(p=.493)$ & $.171(p=.006)$ & $.034(p=.582)$ \\
\hline Big Five: Agreeableness & $-.049(p=.431)$ & $.113(p=.069)$ & $.028(p=.655)$ \\
\hline Big Five: Conscientiousness & $.108(p=.078)$ & $-.147(p=.017)$ & $.227(p<.001)$ \\
\hline \multicolumn{4}{|l|}{ Educational achievement } \\
\hline GCSEs: Mean grade & $.038(p=.643)$ & $-.061(p=.458)$ & $.227(p=.005)$ \\
\hline A-levels: Mean grade & $-.020(p=.831)$ & $.038(p=.688)$ & $.004(p=.969)$ \\
\hline GCSE grade: Art & $.155(p=.071)$ & $-.001(p=.991)$ & $.018(p=.839)$ \\
\hline GCSE grade: English language & $.105(p=.204)$ & $-.069(p=.417)$ & $.370(p<.001)$ \\
\hline GCSE grade: Math & $.027(p=.750)$ & $-.051(p=.553)$ & $.183(p=.031)$ \\
\hline
\end{tabular}

Note. Correlations significant at a nominal level of $p<.05$ are shown in bold. $N$ varies between 241 and 276 for all correlations except those in educational achievement which have $n$ in the range 113 to 154 .

in the analysis with a nominal significance level of $p<.05$, Sex: $t(274)=-2.138, p=.033$, Conscientiousness, $t(274)=$ $2.007, p=.046$, although again, these results would not survive a Bonferroni correction. The conclusion has to be that self-rated drawing ability relates to none of the background variables we have assessed, although it is possible that larger studies might find a relationship to sex or conscientiousness. Of particular importance is that drawing ability did not relate to any of the measures of dyslexia.

Correlates of a history of dyslexia and the spelling test. Table 1 shows correlations of the various background measures with a diagnosis of dyslexia and with the spelling test. By and large the correlations show the same pattern (remembering that dyslexia is indicated by high scores on the diagnosis variable or low scores on the spelling test). A diagnosis of dyslexia and low spelling scores correlates with problems in distinguishing right and left, with a history of dyspraxia, with higher $N$ scores, low $\mathrm{C}$ scores, and poorer achievement at GCSE. Additionally, a history of dyslexia correlated with a history of stuttering, a family history, and higher $\mathrm{O}$ scores, while lower spelling scores correlated with lower English Literature grade at GCSE.

\section{Discussion: Study 1}

Art students differ in their self-rated drawing abilities. However there is no significant correlation of self-rated drawing ability with any of the background factors, in particular with a history of dyslexia or with the spelling test. The lack of signif- icant correlations is also interesting for the personality measures (although it is possible that further, larger studies may replicate the suggestion of a link to conscientiousness). Study 2 investigated drawing ability in more detail by measuring actual drawing performance in subgroups selected for high or low drawing ability and high or low performance on the spelling test.

\section{Study 2}

Study 2 assessed drawing ability in a subgroup of students selected on the basis of self-rated drawing ability and the spelling test. In addition a non-art student control group was included to assess whether the poor drawing art students were similar to controls in their drawing ability.

\section{Method}

Participants. Participants were selected from individuals taking part in Study 1 in a stratified design. Figure 2 shows the self-rated drawing ability in relation to spelling test performance for all participants in Study 1. Participants were selected for Study 2 if they a) had English as a first language; b) had consented to take part in further studies and c) had provided contact information. We also wished to have a balance between the two art schools, with approximately twice as many RCA students as SMU students. Participants were sampled as far as possible to have high $(\geq 3.5)$ or low $(\leq 2.9)$ self-rated drawing 


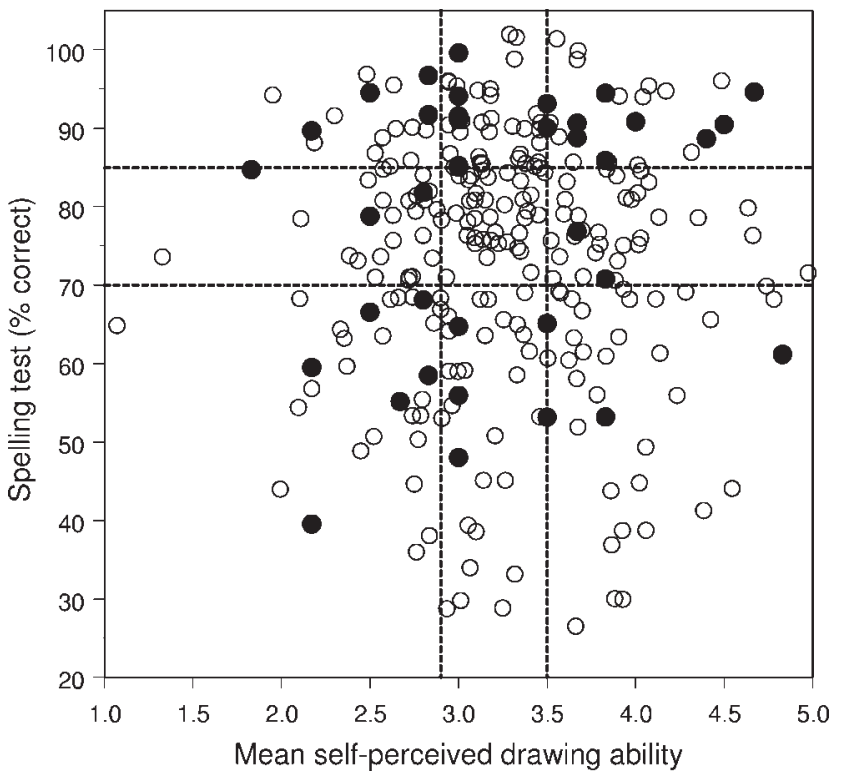

Figure 2. The relationship in art students between perceived drawing ability and the spelling test score (Study 1). Scores have been jittered slightly to avoid overlap between points. Participants who took part in Study 2 are shown as solid points, and the horizontal and vertical lines show the intended selection bands (see text), so that the majority of subjects tested are in one of the four corners.

ability, and high ( $\geq 85 \%$ ) or low ( $\leq 70 \%)$ spelling scores ability, in approximately equal numbers of the four combinations. Occasional dropouts and other practical constraints meant that not all participants met the drawing and spelling criteria exactly.

Control group. As well as the art students, an additional 30 participants were tested who had no history of attending art school. They were obtained from the subject pool of the Department of Psychology, and completed a modified version of the questionnaire which did not ask questions specific to art students.

\section{Drawing and Other Tests}

Materials. Participants were tested in groups of between four and eight. Images were shown either using a digital projector or with participants seated in front of an individual computer monitor. Participants were provided with a block of A3 $(420 \times 297 \mathrm{mms})$, heavy-weight art paper ( $\left.130 \mathrm{~g} . \mathrm{m}^{-2}\right)$, a $0.7 \mathrm{~mm}$ diameter propelling pencil, and an eraser. Each task was carried out on a separate page of the book.

Procedure. The tasks for the participants, in order of presentation, were:

1. Copying of the rey-osterrieth complex figure. Four minutes were allowed for the task. Scoring followed the standard 36-point scheme (Rey \& Osterrieth, 1993; Meyers \& Meyers, 1995), which is reliable (Liberman, Stewart, Seines, \& Gordon, 1994). Previous work (Brunswick, 2007) has shown that the time limit is adequate for both dyslexic and controls.

2. Immediate recall of the rey-osterrieth figure. The ReyOsterrieth figure was removed, participants turned the page of their drawing pad, and after about $30 \mathrm{~s}$, as in the study of Loring,
Martin, Meador, and Lee (1990), were given 3 minutes to draw the figure from memory.

3. "Hand" drawing. Participants were given 5 minutes to make an accurate drawing of a colored photograph of a hand holding a pencil (Figure 3a).

4. Arp drawing. Participants were given 4 minutes to make an accurate drawing of the 1951 lithograph Configuration by Hans Arp (see http://www.williamweston.co.uk/pages/previous/single/ 376/103/1.html). This test was given to assess accuracy of drawing complex curves, and analysis will be left to a further occasion.

5. Malevich drawing. Participants were given 5 minutes to make an accurate drawing of Kazimir Malevich's, 1915 Suprematism With Eight Red Rectangles (Stedelijk Museum, Amsterdam, see Figure $3 b$ ).

6. "House" drawing task. Participants were asked to make accurate drawings of five "houses," similar in structure to those used by Cain (1943) and shown in Figure 4. Each was presented for 1 minute.

7. "Blocks" drawing. Participants were given 5 minutes to make an accurate drawing based on a color photograph of the object made of children's toy blocks shown in Figure 3c.

8. Delayed recall of the rey-osterrieth figure. Participants, who had not been warned that they would be required to do this task, were given 3 minutes to make a drawing of the ReyOsterrieth figure from memory. The delayed recall typically took place about 40 minutes after the first recall.

\section{Evaluation of Drawings}

The "Hand" and "Blocks" drawings. Like Cohen and Jones (2008), we used assessments by both expert and nonexpert assessors, but using a somewhat different method. The drawings made by the 38 art students were assessed by 10 nonexpert judges (assessment A) and five expert judges (assessment B), and the drawings made by the entire set of 68 subjects ( 38 art students and 30 controls) were also assessed by a further nine nonexpert judges
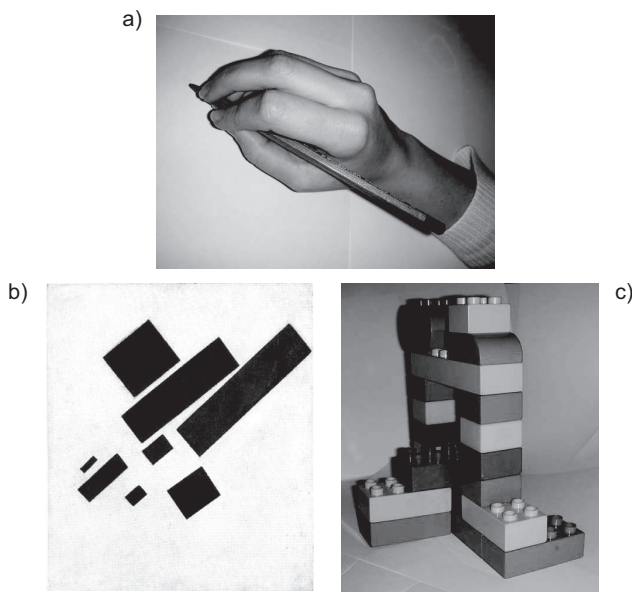

Figure 3. The three images that the participants were asked to copy: a) a photograph of a hand holding a pencil; b) Kasimir Malevich's, 1915 Suprematism With Eight Red Rectangles (see http://commons.wikimedia .org/wiki/File:Malevich-Suprematism.jpg); c) a photograph of an object made by the authors from toy blocks. 


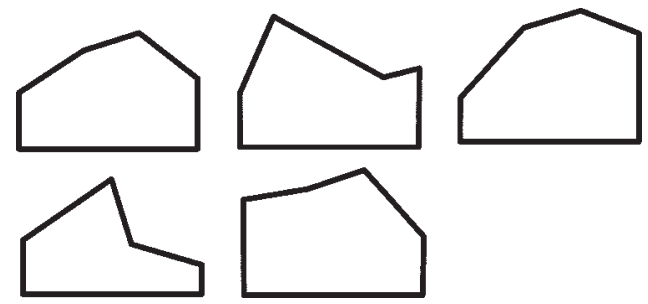

Figure 4. The five "house" figures, similar in structure to those used by Cain (1943).

(assessment C). Nonexpert assessors were a convenience sample of undergraduate and postgraduate students, whereas the expert assessors were teachers of art at the RCA or SMU. Assessments used variants on the card-sort method. For convenience and manageability, the drawings were photographed, reduced in size by $50 \%$, and printed on thick, art-quality card, and sorted by hand on a large table (approximately three meters by two meters).

Assessments A and B. The 38 variants of a picture ("Hand" or "Blocks") were shuffled and placed on the table. The assessors first divided them into three approximately equal groups, with the most proficient drawings to the right, the least proficient drawings to the left, and the remainder in the middle. Assessors were reminded that proficiency, following Cohen and Bennett (1997), meant that the drawings looked like the original, and a copy of the original photograph was left in the middle of the table for guidance. Having sorted the cards into three piles, the assessors subdivided each pile into four further groups reflecting proficiency, so that eventually there were 12 categories across the table from least proficient on the left to most proficient on the right. Assessors were free to move the cards between groups as they wished, were not required to have equal numbers in the 12 categories, and finished when they were satisfied with the 12 groups they had produced. The task was untimed, but typically took about 20 minutes. The drawings were then scored as 12 for the drawings in the most proficient pile through to 1 for those in the least proficient pile.

Assessment C. Assessment of 68 drawings in assessment C meant that a minor variant of the card sort procedure was used. The drawings were shuffled and about 20 or so placed on the table and sorted into 12 groups as in assessments B and C. Further drawings were then laid on the table four or five at a time, and added to the groups until all 68 cards were laid out. As before, assessors could move cards between columns during the process as they saw fit. Scoring was the same as used previously.

Analysis of the house drawing task and the malevich task. All images were photographed digitally with the image filling the camera frame. Drawings were analyzed using a Matlab program which allowed a cross-hair to be placed over key features of the drawings so that horizontal and vertical positions were recorded, and the internal angles of figures and the lengths of the sides could be calculated. The screen image had a resolution of $1024 \times 768$ pixels, and test-retest reliability was of the order of \pm 1 pixel. For the Malevich drawing, measures were taken of the five largest quadrilaterals in the original, the four internal angles of each being measured, along with the lengths of the four sides, which were calculated relative to the lower oblique rising from left to right. A total of 30 angles and 25 relative lengths were assessed. For Cain's "House" drawing task, measures were taken of the five internal angles, and the four sides relative to the horizontal base, for each of the five houses, making a total of 25 angles and 20 lengths.

Angular errors were calculated as absolute degrees (i.e., independent of sign) from the true angle in the reference image. Length errors were more complicated, as they needed to be calculated relative to a predefined reference line in the figure. Consider a roof section in a Cain house which has a true length $L_{t}$, relative to the base (reference) length of $R_{t}$, and let a drawing shows that same roof section with length $L_{d}$, relative to a base (reference) length of $R_{d}$. The roof section is truly $L_{t} / R_{t}$ of the length of the reference section, but it has been drawn as $L_{d} / R_{d}$ of the reference section. The proportional error is therefore $\left(L_{d} / R_{d}-L_{t} / R_{t}\right) /\left(L_{t} / R_{t}\right)$, and can be expressed as an absolute percentage error as abs $\left(100 \times\left(L_{d} / R_{d}-\right.\right.$ $\left.\left.L_{t} / R_{t}\right) /\left(L_{t} / R_{t}\right)\right)$. If therefore a roof length was actually $30 \%$ of the length of the base, but was drawn as $27 \%$ of the length of the base, then the absolute percentage error is $10 \%$ (i.e., abs $(100 \times(33 / 100-$ $30 / 100) /(30 / 100))$. Averaged measures were calculated separately for the 20 angles and 15 lengths in the Malevich, and the 30 angles and 25 lengths in the five House tasks.

Ethics. The study was approved by the Ethical Committee of the Department of Psychology of University College London.

\section{Results}

Participants. The self-rated drawing ability and the spelling test scores of the 38 art school participants in Study 2 are shown as solid black circles in Figure 2. Twenty-five participants were from the RCA and 13 from SMU, representing 13.4\% and $14.4 \%$ of the questionnaire respondents from those schools). Sixteen of the art students were self-classified as good drawers, and 22 as poor drawers, their mean self-rated drawing scores being 3.92 $(S D=.44)$ and $2.71(S D=.35)$ respectively.

Assessment of drawing quality in the hand and blocks pictures. Table 2 shows that the judgments of drawing quality by the experts and the nonexperts were internally reliable. Considering just the drawings by the 38 art students, which were rated by all 24 judges, Cronbach's alpha was .962 and .970 for the Hand and Blocks, values which are comparable with the alpha reliability of the 51 nonexpert judges reported by Cohen and Jones (2008) of 97.

Validation of the self-rated drawing scores. The ratings of the drawings produced in Study 2 allow a validation of the art students' self-rated drawing ability described in Study 1. Figure 5 shows the ratings of the three groups of assessors (A, B, and C) for the high and low self-rated groups of art students, and also for the drawings produced by the control group. The drawings of the good drawing art students were rated higher than those of the poor drawing art students by all three groups of assessors $(t=2.42,36$ $d f, p=.021 ; t=2.04, p=.049 ; t=2.45, p=.019$, respectively). Although the poor drawing art students were less good than the good drawers, it was also the case that they were better than the control students $(t=2.15,50 d f, p=.036)$.

Drawing ability, dyslexia, and spelling ability. For convenience the analysis is restricted to the judgments of those in Assessment C, since these are available for controls as well as art students. Overall there was no correlation between the spelling test score and the ratings of drawings, either overall ( $r=-.023, N=$ $68, p=.852$ ), or in the three groups separately (controls: $r=.069$, 
Table 2

Reliability of the Assessments of Drawing Quality by the Three Groups of Assessors

\begin{tabular}{|c|c|c|c|c|c|}
\hline \multirow[b]{2}{*}{ Assessment } & \multirow[b]{2}{*}{ Assessors } & \multirow[b]{2}{*}{ Drawings } & \multicolumn{2}{|c|}{ Cronbach's alpha } & \multirow{2}{*}{$\begin{array}{c}\text { Correlation of hand and } \\
\text { block ratings within drawers }\end{array}$} \\
\hline & & & Hand drawing & Blocks drawing & \\
\hline $\mathrm{A}$ & 10 non-experts & 38 drawings by art students & .933 & .958 & $r=.651(p<.001, n=38)$ \\
\hline $\mathrm{B}$ & 5 experts & 38 drawings by art students & .886 & .859 & $r=.383(p=.018, n=38)$ \\
\hline $\mathrm{C}$ & 9 non-experts & 68 drawings by 38 art students and 30 controls & .914 & .934 & $r=.619(p<.001, n=68)$ \\
\hline $\mathrm{A}, \mathrm{B}, \& \mathrm{C}$ & All 24 assessors & 38 art students only & .962 & .970 & $r=.616(p<.001, n=38)$ \\
\hline
\end{tabular}

NS; poor drawers, $r=.267$, NS; good drawers, $r=-.124$, NS). Neither was there any difference in the mean rating of drawings by those who had been diagnosed as dyslexic, those who thought they may be dyslexic, or those with no history of dyslexia, either overall, $F(2,64)=.769, p=.468$, or in the three ability subgroups.

Quantitative measures of drawing ability in the house and malevich tasks. Table 3 shows the relationship of the angular and proportional errors in the House drawing task and the Malevich task to the overall ratings of the Hand and Blocks drawings and to the measures of dyslexia and spelling. There are highly significant correlations between the errors made on a simple copying task and the overall quality of the Hand and Blocks drawings. Of interest though is that the correlations are far higher with the Houses task than with the Malevich task. The angular and proportional components of the house task are each significant predictors in their own right of drawing ability (see Figure 6). However multiple regression showed that although the predictive value of angular error was highly significant after taking proportional errors into account, $F(1,65)=9.54, p=.003$, there was no significant effect of proportional errors after taking angular error into account, $F(1,65)=3.400, p=.070$. Although there were three significant correlations between the angle and length errors and the measures

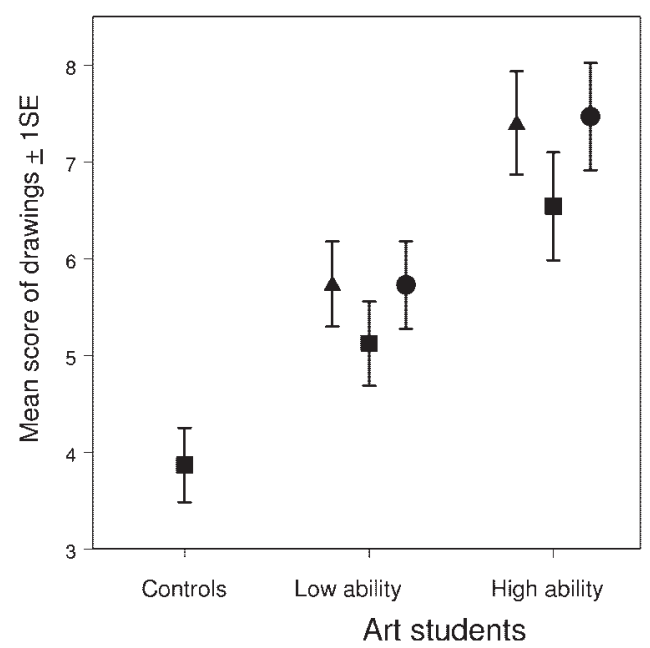

Figure 5. The rating of mean drawing ability $( \pm 1 S E)$ for controls, and high and low self-rated art students by the nonexpert raters in Assessment A ( $\mathbf{\Delta})$, the expert raters in Assessment B ( ), both of whom only rated drawings by art students, and the nonexpert raters in Assessment $\mathrm{C}$ who rated the drawings of all participants ( $\square$ ). of self-perceived drawing ability and a history of dyslexia, none would survive a Bonferroni correction.

The rey-osterrieth task and drawing ability. Across all 68 participants, the mean score for copying the Rey-Osterrieth figure was high $(M=32.8, S D=3.8)$, with only six participants scoring below 30. As expected the scores were lower for immediate recall and delayed recall, (Immediate: $M=22.8, S D=6.1$, range $=$ 4-32; Delayed: $M=22.2, S D=6.5$, range $=0$ to 31 ), the correlation between the immediate and delayed scores being 0.929 . Overall there were no differences in immediate or delayed recall between the controls, the good drawers and the poor drawers, Immediate: $F(2,65)=1.051, p=.356$; Delayed: $F(2,64)=1.98$, $p=.146$. Recall also did not differ in relation to dyslexia diagnosis, Immediate: $F(2,64)=.278, p=.758$; Delayed: $F(2,63)=$ $.342, p=.711$, and neither was there a correlation with the spelling test (Immediate: $r=.002, p=.985$; Delayed: $r=-.120$, $p=.332, n=67)$.

Both the immediate and the delayed Rey-Osterrieth tests showed significant correlations with the overall ratings of the drawings made in Assessment C (Immediate: $r=.408, p=.001$, $n=68$; Delayed, $r=.349, p=.004)$. Multiple regression showed that the Rey-Osterrieth score predicted drawing ability after differences in drawing ability between the three groups were taken into account, $F(2,64)=8.98, p<.001$. However there was no evidence of a difference in slope between the controls, poor drawers and good drawers, $F(2,62)=1.382, p=.259$; see Figure 7 .

Previously in this paper we have shown that both angular errors and proportional errors in drawing simple geometric forms are related to the ability to draw the complex hand and block images. Since recall of the Rey-Osterrieth figure also predicts drawing ability, it is important to note, first, that there is no correlation between immediate Rey-Osterrieth recall and angular or proportion errors $(r=-.153, p=.221, n=68 ; r=-.116, p=.344$, $n=68$, respectively). Second, multiple regression showed that drawing ability was predicted independently by Rey-Osterrieth immediate recall $\left(t_{64}=3.21, p=.002, \beta=.334\right)$, angular errors $\left(t_{64}=-2.38, p=.020, \beta=-.247\right)$ and proportion errors $\left(t_{64}=\right.$ $-2.83, p=.006, \beta=-.296)$. The three variables together accounted for about one third of the total variance in the ratings of the drawing $\left(R=.578, R^{2}=.334\right.$, Adjusted $\left.R^{2}=.303\right)$.

Other researchers (Helland \& Asbjørnsen, 2003) have suggested that recall of the Rey-Osterrieth figure was impaired in a group of dyslexic readers who also had poor mathematical ability. We therefore looked at Rey-Osterrieth performance in our art students in relation to grade achieved at GCSE math. Although the numbers were relatively small (many students coming from abroad and therefore not having taken GCSEs), those with higher mathemat- 
Table 3

Correlations of the Detailed Measures of Errors in Drawing Lengths and Angles in Relation to Self-Rated Drawing Ability, SelfPerceived Drawing Ability, the Spelling Test, and a History of Dyslexia

\begin{tabular}{|c|c|c|c|c|}
\hline \multirow[b]{2}{*}{$\begin{array}{c}\text { Drawing tasks carried out by all } \\
\text { subjects }\end{array}$} & $\begin{array}{l}\text { Summed scores of hand and blocks } \\
\text { drawings (all participants) }\end{array}$ & $\begin{array}{l}\text { Students' self-perceived drawing } \\
\text { ability (art students only) }\end{array}$ & Spelling test & $\begin{array}{l}\text { History of } \\
\text { dyslexia }\end{array}$ \\
\hline & $N=68$ & $N=38$ & $N=68$ & $N=68$ \\
\hline Angular error in drawing (overall) & $-.390(p=.001)$ & $-.197(p=.230)$ & $-.161(p=.185)$ & $-.245(p=.044)$ \\
\hline Angular drawing error (Houses) & $-.423(p<.001)$ & $-.176(p=.292)$ & $-.169(p=.168)$ & $-.145(p=.242)$ \\
\hline Angular drawing error (Malevich) & $-.126(p=.310)$ & $-.179(p=281)$ & $-.078(p=.529)$ & $-.247(p=.044)$ \\
\hline Length drawing error (overall) & $-.333(p=.006)$ & $-.202(p=.218)$ & $-.124(p=.309)$ & $-.046(p=.710)$ \\
\hline Length drawing error (Houses) & $-.325(p=.007)$ & $-.185(p=.614)$ & $-.083(p=.501)$ & $.026(p=.836)$ \\
\hline Length drawing error (Malevich) & $-.103(p=.406)$ & $-.414(p=.010)$ & $-.140(p=.252)$ & $.060(p=.629)$ \\
\hline
\end{tabular}

ical grades had significantly better immediate and delayed recall of the figure $(r=.427, n=28, p=.023 ; r=.566, N=27, p=$ $.002)$. There was though no correlation of math grade with initial copying of the figure $(r=-.004, N=28, p=.984)$.

\section{General Discussion}

Drawing accurately and fluently is a difficult skill to learn, and while it still underpins many of the visual arts, changing practices in those disciplines means that there are now students who cannot draw well but nevertheless who would like to draw well. An important step in achieving that goal is to understand both how people learn to draw and why some have more difficulties than others.

The reasons that some individuals, trained or untrained, are better at drawing than others is relatively little discussed in the literature. As with any complex skill, be it motor, sensory or cognitive, it is almost certainly the case that excellence in drawing requires the 10,000 or so hours of practice that go into becoming an expert at most skills (Ericsson, Krampe, \& Tesch-Römer, 1993; Simon \& Chase, 1973; Chi, Glaser, \& Farr, 1988). There is however a recurrent belief that while some people have an innate talent for drawing, others simply do not, and hence their inability to draw is immediately explained. So prevalent is the myth that Leo Duff felt it necessary to remind her readers that, "All drawing is a serious business. How naive to think that the simple and minimal line placed on a page by Picasso, or the slick Leicester Square caricature of a tourist, were achieved without the backing of hours, days, weeks of "practice"" (Duff \& Davies, 2005). Practice has many effects, one of which is to provide a repertoire of automatic, unconscious procedures that can be invoked fluently and easily. In asking what characterized a group of good (nonprofessional) drawers, Van Sommers (1984), comments that "although inevitably they use more successful strategies, they also seem to have a capacity to use strategies that lead many other subjects into trouble." Or perhaps to put it another way, they have more automatic routines that they can invoke successfully, those

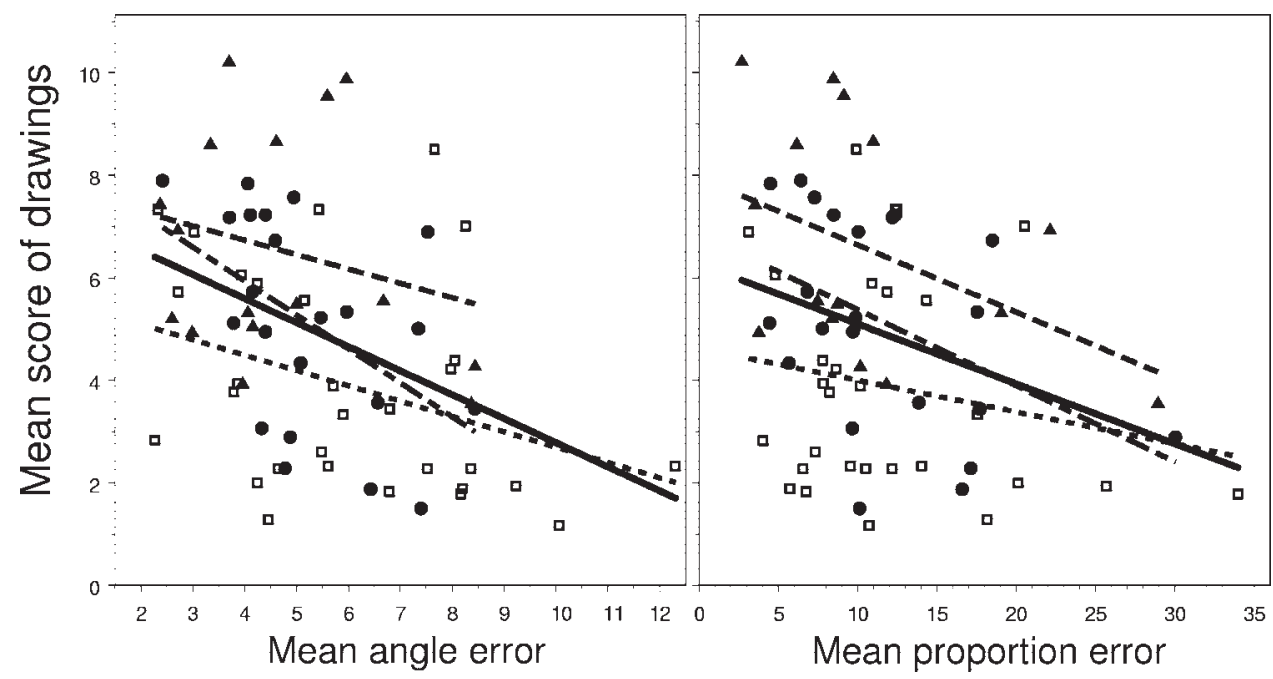

Figure 6. Ratings of mean drawing ability by the judges in Assessment $\mathrm{C}$ in relation to angular errors (left) and proportional errors (right) on the House task of Cain (1943), separately for the controls ( $\square$ ), and high ( $\mathbf{\Delta}$ ) and low (O) self-rated art students. The dashed lines are for the controls, low and high self-rated art students (and are in that order from bottom to top), and the solid black line is for all participants. 


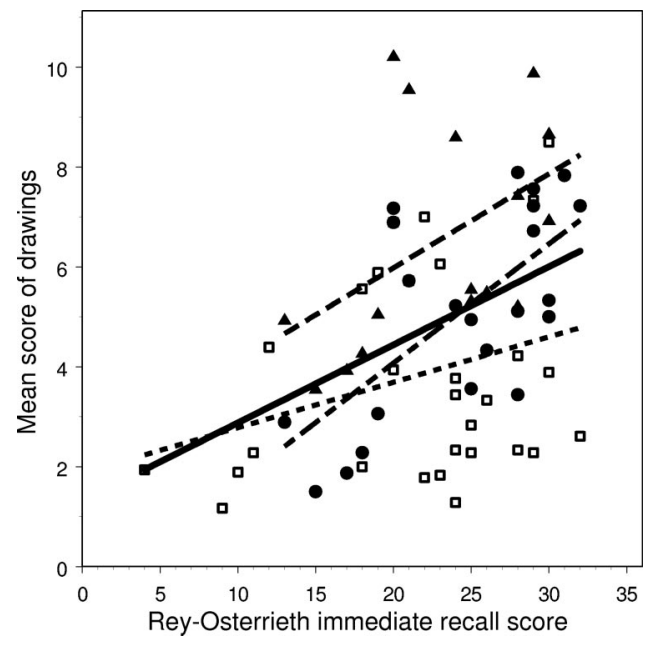

Figure 7. Ratings of mean drawing ability by the judges in Assessment $\mathrm{C}$ in relation to the immediate recall score of the Rey-Osterrieth figure, separately for the controls $(\square)$, and high $(\mathbf{\Delta})$ and low (@) self-rated art students. The dashed lines are for the controls, low and high self-rated art students (and are in that order from bottom to top), and the solid black line is for all participants.

routines being acquired through extensive practice. The present study has not explicitly assessed the total time involved in practice, and that is a shame, and any future study would benefit from it.

The present study does however find a number of useful and important results. First, it is clear that art students have insight into whether they are good at drawing or not, and the validity of those insights is confirmed when self-perceptions are compared with actual performance on a series of drawing tests. It is also of practical importance that even the poor drawing art students are on average better than a control group of non-art students. The implication is that even in the poor drawers, some skills are present, albeit not at the more sophisticated level found in the good drawers, and those skills might form the basis for interventions to improve drawing further.

Our study was driven originally by the possibility that poor drawing ability might be related to dyslexia or other problems with reading. However we found no evidence for a role of dyslexia, either in Study 1 or in Study 2. The conclusion therefore has to be that in general dyslexia has little or no relationship to drawing ability in art students. A small proviso does however to be made in that it is possible, particularly given the association of mathematics achievement and Rey-Osterrieth performance in our data, as was found elsewhere (Helland \& Asbjørnsen, 2003), that there is a subset of dyslexics with mathematical problems who are particularly poor at drawing. Our data do not have adequate power to search for such a group, and we are therefore carrying out a separate study to look at the question more directly. The reason overall that so many art students are dyslexic still requires explanation, but it does seem unlikely that people with dyslexia have either special skills for drawing, or particular problems with making visual representations of the world.

An intriguing feature of the study is the almost total lack of correlation of our background variables with self-reported drawing ability, despite the measure of ability being both internally reliable and validated against actual performance on a range of drawing tasks. Drawing ability did not correlate with handedness, right-left problems, parental attitudes toward art, dyslexia, dyspraxia or stuttering/stammering, aesthetic behaviors in general, educational achievement, sex, or the Big Five personality factors. Study 1 was large, and therefore had reasonable power for excluding relatively small correlations, and therefore the nonsignificant correlations help to exclude a host of explanations for the reasons some art students may have troubles in drawing.

The experimental part of our study was important, not only because it validated the self-rated perceptions of drawing ability, but because it allowed a more detailed examination of underlying processes in drawing. The main tasks of making visually accurate representations of the Hand and the Blocks had high face validity to art students, and even if somewhat stilted, they are genuine drawing tasks. Furthermore, judges, both expert and nonexpert, were reliable in assessing their representational quality. Although it might have been preferable to have had more complex, threedimensional scenes, our present choices are similar in many ways to those of Cohen and Bennett (1997), and like their tasks had the advantage of being replicable, administrable in groups, and being easy for nonexperts to assess reliably.

One of the tasks, Cain's House task (Cain, 1943), explicitly looked at the low level processes of accurately representing angles and proportional relationships, and one of the other tasks, that of copying the eight near-rectangles in a Malevich painting, implicitly assessed the same processes. Overall it is clear that accuracy in drawing angles and proportions correlates with ability on the Hand and Blocks drawing tasks, although a more detailed analysis suggests that it is only performance in Cain's house task which is doing the prediction. One possibility for the failure of the Malevich task is that participants were more concerned with representing the relationship between the eight rectangles rather than the precise shapes of the rectangles themselves; certainly that issue needs addressing in the future.

Cain's house task has two separate components of representing angles and proportions. To some extent these are inevitably correlated (although it is worth noting that a "house" for which just the side walls were stretched upward would fail on its proportional representation but would be accurate in its angular representations). Nevertheless it does seem that angular representations are statistically more important as predictors of drawing ability than are proportions, although of course in practice both processes go on at the same time. Why angles should be better than proportions is far from clear. Conventional teaching of drawing often emphasizes proportions, measured in the traditional way with the pencil at the end of the outstretched arm and held vertically or horizontally (and with the vertical often assured by a plumb line). Measuring angles using such a method is indirect, and may well be inefficient. The direct measurement of angles (e.g., by rotating a pencil until its angle matches that of an object) is also difficult, as there is no reference angle against which the pencil can be compared. It is therefore possible that the veridical perception of phenomenal angles is the more difficult task, and hence those who have mastered it better are also those who are better at making representational drawings.

Our study also found that visual memory, as assessed by the immediate and the delayed reproduction of the Rey-Osterrieth figures, is related to the production of visually accurate drawings. 
That result is similar to the finding of Jones (1922). We found it interesting that Jones (1922) also reported that his drawing task correlated .69 with a measure of perspective perception. However, the correlation of his memory task and perspective task was .85 , meaning that the partial correlation of drawing with perspective, taking into account visual memory, was only -.053. In contrast, the effect of visual memory remained significant after taking perspective into account, the partial correlation being .638 . In our study there was no correlation between performance on the Rey-Osterrieth task and on the Cain task, so that performance on the reproduction of angles and proportions and on the ReyOsterrieth figure are independent predictors of drawing ability, together accounting for almost a third of the total variance in performance. It is also important to note-as seen in Figure 7-that although visual memory on the Rey-Osterrieth task correlates with drawing ability in controls, poor drawers and good drawers, mean recall on the Rey-Osterrieth task does not differ between the three groups. The implication is perhaps that visual memory is not trainable, but that it is a substrate on which drawing performance is subsequently built.

As well as wishing to understand why some art students cannot draw well, we would also like to be able to help art students who cannot draw but wish to draw. Our study raises several possibilities on that front. An interesting parallel skill to drawing is that of singing. Many people have problems in singing properly, and often describe themselves as "tone-deaf," despite actually having adequate musical perceptual processes (Wise \& Sloboda, 2008; Wise, Sloboda, \& Peretz, 2007). Indeed much of the problem, Sloboda has suggested, comes from novice singers often undertaking what are actually excessively difficult tasks, so that they then fail to produce a high-level result, and the outcome is that they become discouraged and demotivated. A remedial solution adopted by many music (and art) teachers, and educators in general, is to produce a graded series of tasks, so that success can be seen to be achieved on simpler tasks before more complex ones are introduced. Such an approach may well be of use in poor drawing art students, where success is required in simple tasks in order to motivate students for subsequent more complex tasks. The teaching of complex tasks often requires the breaking down of rich, multidimensional tasks such as singing, into their separate components (pitch, rhythm, reading of music, voice control, and breathing, etc.). A possibility raised by the present study is that art students may benefit from the explicit teaching of techniques for carrying out very low level copying skills, such as in accurately representing angles and proportions. Whether visual memory can also be trained is another matter, but if so it may also improve drawing ability.

\section{References}

Aaron, P. G., \& Guillemard, J.-C. (1993). Artists as dyslexics. In D. M. Willows, R. S. Kruk, \& E. Corcos (Eds.), Visual processes in reading and reading disabilities (pp. 393-415). Hillsdale NJ: Erlbaum.

Alias, M., Gray, D. E., \& Black, T. R. (2002). Attitudes towards sketching and drawing and the relationship with spatial visualisation ability in engineering students. International Education Journal, 3, 165-175.

Arnheim, R. (1980). The puzzle of Nadia's drawings. Arts in Psychotherapy, 7, 79-85.

Berger, J. (2005). Berger on drawing (Edited by Jim Savage). Aghabullogue, County Cork: Occasional Press.
Bertrand, J., Mervis, C. B., \& Eisenberg, J. D. (1997). Drawing by children with Williams syndrome: A developmental perspective. Developmental Neuropsychology, 13, 41-68.

Brunswick, N. (2007). Visuospatial ability in adults with developmental dyslexia. Stavanger: 1st Stavanger Reading and Writing Conference, Stavanger September 2007.

Cain, T. I. (1943). The objective measurement of accuracy in drawings. American Journal of Psychology, 56, 32-53.

Cain, T. I. (1946). Psychology of drawing and painting. In D. D. Runes \& H. G. Schrickel (Eds.), Encyclopedia of the Arts (pp. 817-820). New York: Philosophical Library.

Chambliss, C. A., \& Moulton, L. R. (1987). Efficacy of Edwards's drawing training techniques. Perceptual and Motor Skills, 64, 618.

Chi, M. T. H., Glaser, R., \& Farr, M. J. (1988). The nature of expertise. Hillsdale, NJ: Erlbaum.

Cohen, D. J., \& Bennett, S. (1997). Why can't most people draw what they see? Journal of Experimental Psychology: Human Perception and Performance, 23, 609-621.

Cohen, D. J., \& Jones, H. E. (2008). How shape constancy relates to drawing accuracy. Psychology of Aesthetics, Creativity, and the Arts, 2, $8-19$.

Craggs, J. G., Sanchez, J., Kibby, M. Y., Gilger, J. W., \& Hynd, G. W. (2008). Brain morphology and neuropsychological profiles in afamily displaying dyslexia and superior nonverbal intelligence. Cortex, 42, 1107-1118.

Duff, L., \& Davies, J. (2005). Drawing-the process. Bristol: Intellect Books.

Edwards, B. (1989). Drawing on the right side of the brain: A course in enhancing creativity and artistic confidence. Rev. ed. New York: Perigee Books.

Ericsson, K. A., Krampe, R. T., \& Tesch-Römer, C. (1993). The role of deliberate practice in the acquisition of expert performance. Psychological Review, 100, 363-406.

Everatt, J. (1997). The ability and disabilities associated with adult developmental dyslexia. Journal of Research in Reading, 20, 13-21.

Fein, D., Lucci, D., \& Waterhouse, L. (1990). Brief report: Fragmented drawings in autistic children. Journal of Autism and Developmental Disorders, 20, 263-269.

Furnham, A., \& McManus, I. C. (2004). Student attitudes to university education. Higher Education Review, 36, 29-38.

Furnham, A., McManus, I. C., \& Scott, D. (2003). Personality, empathy and attitudes to animal welfare. Anthrozoös, 16, 135-146.

Gill, E. (1940). Autobiography: Quod Ore Sumpsimus. London: Jonathan Cape.

Golomb, C., \& Schmeling, J. (1996). Drawing development in autistic and mentally retarded children. Visual Arts Research, 22, 5-18.

Grant, D. (2008). That's the way I think: Dyslexia and dyspraxia explained. London: David Fulton.

Hannay, H. J., Ciaccia, P. J., Kerr, J. W., \& Barrett, D. (1990). Self-report of right-left confusion in college men and women. Perceptual and Motor Skills, 70, 451-457.

Hassler, M. (1990). Functional cerebral asymmetries and cognitive abilities in musicians, painters, and controls. Brain and Cognition, 13, 1-17.

Helland, T., \& Asbjørnsen, A. (2003). Visual-sequential and visuo-spatial skills in dyslexia: Variations according to language comprehension and mathematics skills. Child Neuropsychology, 9, 208-220.

Hermelin, B., Pring, L., \& Heavey, L. (1994). Visual and motor functions in graphically gifted savants. Psychological Medicine, 24, 673-680.

Ivins, W. M., Jr. (1938). The rationalization of sight [reprinted 1973, Da Capo Press, New York]. New York: Metropolitan Museum.

Jones, E. E. (1922). The correlation of visual memory and perception of perspective with drawing ability. School and Society, 15, 174-176.

Jordan, K., Wüstenberg, T., Jaspers-Feyer, F., Fellbrich, A., \& Peters, M. (2006). Sex differences in left/right confusion. Cortex, 42, 69-78. 
Lanthony, P. (1995). Les peintres gauchers. Revue Neurologique, 151, $165-170$.

Lanthony, P. (2005). Les peintres gauchers. Clamecy: L'age d'homme.

Liberman, J., Stewart, W., Seines, O., \& Gordon, B. (1994). Rater agreement for the Rey-Osterrieth complex figure test. Journal of Clinical Psychology, 50, 615-624.

Loring, D. W., Martin, R. C., Meador, K. J., \& Lee, G. P. (1990). Psychometric construction of the Rey-Osterrieth complex figure: Methodological considerations and interrater reliability. Archives of Clinical Neuropsychology, 5, 1-14.

Magnus, R., \& Laeng, B. (2006). Drawing on either side of the brain. Laterality: Asymmetries of Body, Brain and Cognition, 11, 71-89.

Makuuchi, M., Kaminaga, T., \& Sugishita, M. (2003). Both parietal lobes are involved in drawing: A functional MRI study and implications for constructional apraxia. Cognitive Brain Research, 16, 338-347.

Mati-Zizzi, H., \& Zafiropoulou, M. (2003). Visuomotor coordination and visuospatial working memory of children with specific reading disabilities: A study using the Rey-Osterrieth complex figure. Perceptual and Motor Skills, 97, 543-546.

Maynard, P. (2005). Drawing distinctions: The varieties of graphic expression. Ithaca, NY: Cornell University Press.

McGregor, I. (1990). Unusual drawing development in children: What does it reveal about children's art? In C. Case, T. Dalley, \& et al (Eds.), Working with children in art therapy (pp. 39-53). London: Tavistock/ Routledge.

McMahon, J. A. (2002). An explanation for normal and anomalous drawing ability and implications for research on perception and imagery. Visual Arts Research, 28, 38-52.

McManus, I. C., \& Drury, H. (2004). The handedness of Leonardo da Vinci: A tale of the complexities of lateralisation. Brain and Cognition, $55,262-268$.

McManus, I. C., \& Furnham, A. (2006). Aesthetic activities and aesthetic attitudes: Influences of education, background and personality on interest and involvement in the arts. British Journal of Psychology, 97, $555-587$.

McManus, I. C., Martin, N., Stubbings, G. F., Chung, E. M. K., \& Mitchison, H. M. (2004). Handedness and situs inversus in primary ciliary dyskinesia. Proceedings of the Royal Society of London, Series B, 271, 2579-2582.

McManus, I. C., Mitchison, H. M., Chung, E. M. K., Stubbings, G. F., \& Martin, N. (2003). Primary ciliary dyskinesia (Siewert's/Kartagener's Syndrome): Respiratory symptoms and psycho-social impact. BMC Pulmonary Medicine, 3, 4. www.biomedcentral.com/1471-2466/3/4/ abstract

Mebert, C., \& Michel, G. (1980). Handedness in artists. In J. Herron (Ed.), Neuropsychology of left-handedness (pp. 273-278). New York: Academic Press.

Meyers, J. E., \& Meyers, K. R. (1995). Rey Complex figure test and recognition trial. Psychological Assessment Resources.

Milbrath, C., \& Siegel, B. (1996). Perspective taking in the drawings of a talented autistic child. Visual Arts Research, 22, 56-75.

Miles, T. R. (1993). Dyslexia: The pattern of difficulties. London: Whurr.

Miller, K. (2006). Do we know what we like? Review of "Lines of Enquiry: Thinking through drawing," Kettle's Yard, Cambridge. Times Literary Suppl, August 18th, 20-21.

Minshew, N. J., \& Goldstein, G. (2001). The pattern of intact and impaired memory functions in autism. Journal of Child Psychology and Psychiatry, 42, 1095-1101.

Mottron, L., \& Belleville, S. (1993). A study of perceptual analysis in a high-level autistic subject with exceptional graphic abilities. Brain and Cognition, 23, 279-309.

Mottron, L., \& Belleville, S. (1995). Perspective production in a savant autistic draughtsman. Psychological Medicine, 25, 639-648.

O'Connor, N., \& Hermelin, B. (1987). Visual memory and motor pro- grammes: Their use by idiot-savant artists and controls. British Journal of Psychology, 78, 307-323.

Rankin, Q., Riley, H., \& Davies, M. (2005). The effect of dyslexia and dyspraxia on the cognitive modelling process within the context of art and design. Part One: Drawing on drawing. In Include 2005: Conference on Inclusive Design London: Royal College of Art.

Rankin, Q., Riley, H., \& Davies, M. (2007). Including Dyslexics: Indicators of Dyslexia in Art Students' Drawings. In J. Myerson \& C. Bilsland (Eds.), Include 2007: Conference on inclusive design. London: Royal College of Art.

Read, H. (1956). Picasso at 75. The Times, October 27th, 7.

Rey, A., \& Osterrieth, P. A. (1993). Translations of excerpts from Andre Rey's Psychological examination of traumatic encephalopathy and P. A. Osterrieth's The Complex Figure Copy Test. Clinical Neuropsychologist, 7, 4-21.

Riley, H. (2008). Drawing: Towards an intelligence of seeing. In S. Garner (Ed.), Writing on drawing. Bristol: Intellect.

Rosenblatt, E., \& Winner, E. (1988). Is superior visual memory a component of superior drawing ability? In L. K. Obler \& D. Fein (Eds.), The exceptional brain: Neuropsychology of talent and special abilities (pp. 341-363). New York: Guilford Press.

Ruskin, J. (1857). The elements of drawing. London: Smith, Elder, \& Co.

Simon, H. A., \& Chase, W. G. (1973). Skill in chess. American Scientist, 61, 394-403.

Snyder, A. W., Mulcahy, E., Taylor, J. L., Mitchell, D. J., Sachdev, P., \& Gandevia, S. C. (2003). Savant-like skills exposed in normal people by suppressing the left fronto-temporal lobe. Journal of Integrative Neuroscience, 2, 149-158.

Snyder, A. W., \& Thomas, M. (1997). Autistic artists give clues to cognition. Perception, 26, 93-96.

Speed, H. (1913). The practice and science of drawing. London: Seeley, Service \& Co.

Thompson, B. (1995). Stepwise regression and stepwise discriminant analysis need not apply here: A guidelines editorial. Educational and Psychological Measurement, 55, 525-534.

Van Sommers, P. (1984). Drawing and cognition: Descriptive and experimental studies of graphic production processes. Cambridge: Cambridge University Press.

von Karolyi, C. (2001). Visual-spatial strength in dyslexia: Rapid discrimination of impossible figures. Journal of Learning Disabilities, 34, 380-391.

von Karolyi, C., \& Winner, E. (2004). Dyslexia and visual spatial talents: Are they connected? In T. M. Newman \& R. J. Sternberg (Eds.), Students with both gifts and learning disabilities (pp. 95-118). New York: Springer.

Waterhouse, L. (1988). Extraordinary visual memory and pattern perception in an autistic boy. In The exceptional brain: Neuropsychology of talent and special abilities (pp. 325-338). New York: Guilford Press.

West, T. (1997). In the mind's eye: Visual thinkers, gifted people with dyslexia and other learning difficulties, computer images and the irony of creativity. New York: Prometheus Books.

Winner, E., \& Casey, M. B. (1992). Cognitive profiles of artists. In G. C. Cupchik \& J. László (Eds.), Emerging visions of the aesthetic process. Psychology, semiology, and philosophy (pp. 154-170). Cambridge: Cambridge University Press.

Winner, E., Casey, M. B., DaSilva, D., \& Hayes, R. (1991). Spatial abilities and reading deficits in visual art students. Empirical Studies of the Arts, 9, 51-63.

Winner, E., von Karolyi, C., \& Malinsky, D. (2000). Dyslexia and visuospatial talents: No clear link. International Dyslexia Association Newsletter, Spring, 27-30.

Winner, E., von Karolyi, C., Malinsky, D., French, L., Seliger, S., Ross, E., 
\& Weber, E. (2001). Dyslexia and visual-spatial talents: Compensation vs deficit model. Brain and Language, 76, 81-110.

Wise, K., Sloboda, J., \& Peretz, I. (2007). Progress in understanding 'tone deafness.' British Academy Review, Issue, 10, 52-54.

Wise, K. J., \& Sloboda, J. A. (2008). Establishing an empirical profile of self-defined 'tone-deafness': Perception, singing performance and selfassessment. Musicae Scientiae, 12, 3-26.
Woolf, U., \& Lundberg, I. (2002). The prevalence of dyslexia among art students. Dyslexia, 8, 34-42.

Received March 9, 2009

Revision received June 1, 2009

Accepted June 1, 2009 